\title{
Masculinidades entre matar e morrer: o que a saúde tem a ver com isso?
}

I ${ }^{1}$ Helen Barbosa dos Santos, ${ }^{2}$ Henrique Caetano Nardi I

Resumo: As causas externas são as principais responsáveis pelo adoecimento e pela morte na população masculina brasileira jovem. Especificamente em relação aos homens inseridos no contexto criminal, se não morrem em decorrência da violência urbana, lhes é destinada a violência do cárcere. A fim de compreender o diagrama de forças implicado na produção de masculinidades criminalizadas, buscamos entender que saúde é possível para essas masculinidades marcadas pela morte física ou pela morte social. $\mathrm{O}$ estudo inspira-se metodologicamente na perspectiva teórica de Michel Foucault, buscando analisar, no contexto biopolítico brasileiro, a saúde dos homens privados de liberdade sob a luz da Política de Atenção Integral à Saúde do Homem (PNAISH), do Plano Nacional de Atenção à Saúde no Sistema Penitenciário e da atual Política Nacional de Atenção Integral à Saúde das Pessoas Privadas de Liberdade no Sistema Prisional. A análise aponta para as interseccionalidades de raça e classe social na produção do adoecimento. Os dados atuais revelam que muitos homens que adoecem na prisão morrem fora dela por falta de acesso ao cuidado em saúde. Nesta senda, a Política Nacional de Atenção Integral à Saúde no Sistema Penitenciário recoloca a discussão dos direitos à saúde, sobretudo no que tange à integralidade e à intersetorialidade.

> Palavras-chave: masculinidades; prisão; saúde do homem.

\author{
1 Secretaria Estadual de Saúde \\ (SES-RS) Saúde do Homem. \\ Porto Alegre-RS, Brasil. \\ Endereço eletrônico: helenpsi@ \\ yahoo.com.br \\ 2 Programa de Pós-Graduação \\ em Psicologia Social e \\ Institucional, Universidade \\ Federal do Rio Grande do \\ Sul. Porto Alegre-RS, Brasil. \\ Endereço eletrônico: hcnardi@ \\ gmail.com
}

Recebido em: 29/08/2013 Aprovado em: 29/07/2014 
Um aspecto pouco explorado no debate em torno da Política Nacional de Atenção Integral à Saúde do Homem (PNAISH), instituída em 2009 enquanto uma política de saúde que se atém à saúde do corpo social masculino, priorizando a faixa etária dos 20 anos aos 59 anos, é a morbimortalidade associada às causas externas, como indica o trabalho de Wagner Figueiredo (2005), ressaltando os acidentes de trânsito e os homicídios. Mesmo que os princípios e diretrizes da PNAISH sejam baseados em dados epidemiológicos e apontem para os fatores de risco associados aos indicadores de morbimortalidade, a política tomou como seu objeto central o câncer de próstata. Assim, problematizar a saúde do homem e a questão social da violência é uma discussão necessária, como indica Sérgio Carrara $(2005 ; 2009)$, ao contextualizar as tensôes presentes na constituição desta política de saúde.

Buscamos aqui, então, a partir de uma perspectiva foucaultiana, diagramar as relações de poder que atravessam a produção social de masculinidades marcadas pelo fenômeno da violência; masculinidades que, quando não morrem no espaço público, são encarceradas no sistema prisional. ${ }^{1}$ Veremos que a morte social é um imperativo no cotidiano da prisão e que, para sobreviver, os homens necessitam reiterar uma masculinidade que se fortalece a partir de relações conflituosas e hierárquicas. Nessa direção, utilizamo-nos do espaço prisional como território emblemático de homens considerados infames. Parafraseando Foucault em seu livro Em defesa da sociedade, questiona-se: que vidas importam para a nação brasileira? Os "[...] corpos que importam", os "sujeitos aceitos [...]”, (LOURO, 2004, p. 15) são aqueles que obedecem a normas regulatórias. Aqueles que oscilam, hesitam, inventam novos caminhos e ousam trilhá-los, são suspeitos, no limite, descartáveis, restos.

Também partimos do entendimento de gênero pela analítica queer para pontuarmos a produção de masculinidades destituídas de determinados direitos de acesso à saúde. Nessa direção, Richard Miskolci (2009), ao analisar a cultura ocidental, dissolve a noção dos sujeitos sexuais como estáveis para focar nos processos classificatórios, hierarquizadores que normalizam os comportamentos. Judith Butler (2008) afirma que não há sexo que não seja já, desde sempre, gênero. Para ela, todos os corpos são socialmente generificados, o que significa dizer que 
não há "corpo natural” preexistente à sua inscrição cultural. Assim, gênero não é

algo que alguém é, mas algo que se faz em ato, ou, mais precisamente, em uma sequência de atos, um "fazer" que produz um "ser".

Apesar das masculinidades estarem sempre em estado de fluidez, de deriva (SEFFNER, 2003), naturaliza-se o masculino atribuído a características fixas pelas normas de gênero a partir da dinâmica da dominação, da agressividade. Cynthia Sarti (2006) afirma que vítima e agressor são construções simbólicas atravessadas pelas relações de gênero, sobretudo diante da associação naturalizada entre violência e masculinidade, tão presente no imaginário social, a qual identifica o homem como agressor ao fazer da violência um atributo da masculinidade. $\mathrm{Ou}$ seja, o homem é réu antes mesmo de cometer o ato violento.

Nesta senda, questionamos: que saúde é possível para masculinidades deslegitimadas pela sociedade, quando o que lhes resta é apenas o estatuto de serem machos no interior desse regramento que impõe a violência? Como vem se inscrevendo a produção de saúde para as masculinidades que, quando não morrem nas ruas, têm sua morte social materializada no território prisional?

Existe uma tensão na produção da relação masculinidade e saúde, pois, de acordo com o documento oficial da PNAISH, o homem não cuida de sua saúde e acessa os serviços de emergência em vez dos serviços de atenção básica em saúde, onerando a saúde pública. Contribuindo para esse debate, a pesquisa de Márcia Tereza Couto et al. (2010) averiguou que, nas representaçôes dos profissionais de saúde da atenção básica, os homens não foram reconhecidos como potenciais sujeitos de cuidado. Os serviços da atenção básica em saúde se apresentam, tanto em seu espaço físico como em suas agendas de atendimento, como serviços essencialmente voltados a mulheres e crianças.

Ademais, de acordo com Cynthia Sarti (2006), no âmbito das políticas de saúde, enfatiza-se a figura da vítima como sendo a mulher, a criança e o/a idoso/a. No discurso médico e jurídico, "violência” remete, sobretudo, à violência doméstica e familiar, na qual há uma cristalização dos lugares de vítima e agressor. Então, que casos de violência têm inteligibilidade no campo da saúde pública? A relação violenta estabelecida entre homens é uma relação ambígua, pois se os homens são naturalizados como potenciais réus do ato em si, como designar quem é considerado a vítima? O branco? O negro? E se forem dois negros? Salienta-se que as maiores vítimas de mortalidade são homens, negros, entre 14 a 24 anos 
de idade. Dentre a mortalidade por causas externas, o mapa da violência de 2010 aponta, conforme Julio Waiselfisz (2011), que dos 49.932 homicídios registrados pelo Sistema de Informações de Mortalidade (SIM) do DATASUS, 45.617 eram homens $(91,4 \%)$ e 4.273 mulheres $(8,6 \%)$. Historicamente, essas proporções não têm mudado significativamente de um ano para outro.

Marcos Nascimento et al. (2011) inferem que a alta mortalidade masculina entre os jovens pobres revela em parte a discriminação à brasileira, ou seja, uma conduta que legitima a cor e a classe como critérios que tornam a pessoa um perigo em potencial. Diante de tantas restrições sociais, a violência é uma tática de poder que garante ao homem seu lugar de "macho". É o que Daniel WelzerLang (2009) chamou de "retorno virilista", citando como exemplo os jovens dos meios populares desempregados, sem trabalho e sem dinheiro, que se lançam em açôes violentas entre eles e contra outras pessoas para provar sua virilidade.

Nessa direção, ressalta-se que, para além do fato de jovens negros e pardos serem os mais atingidos pela morte por causas externas, Cecília Coimbra (2005) e Marcos Nascimento et al. (2011) afirmam que estes são a população principal dos presídios do Brasil. O banco de dados do Ministério da Justiça (2012) confirma essa afirmação, pois 196.267 homens apenados são pardos, 76.906 são negros e 162.256 brancos. Além disso, dados recentes do Ministério da Justiça indicam que, dos 476.805 presos no Brasil, 131.333 têm entre 18 e 24 anos. Esses dados colocam em movimento a noção da raça na sua interseccionalidade com educação, gênero e classe na produção de masculinidades criminosas.

Através de distintas redes de tensionamentos, o sujeito criminoso é produzido por um modo de subjetivação que o situa em um mundo à parte, no avesso da norma que produz o cidadão de bem. Ao não colocar no espaço público o debate da produção social da violência, produz-se um sujeito que carrega o crime em sua própria alma; no limite da sujeição criminal, o sujeito criminoso, potencialmente perigoso, pode até mesmo ser morto, pois não é uma vida legítima (MISSE, 2010). "A morte do outro não é simplesmente a minha vida, na medida em que seria minha segurança pessoal: a morte da raça ruim, da raça inferior (ou do degenerado, do anormal), é que vai deixar a vida em geral mais saudável e pura." (FOUCAULT, 2008, p. 305). Assim, aquele retratado como mau, inferior, aquele que se deve evitar, ou mesmo aniquilar, produz um dos núcleos do corpo social masculino. 
A fim de problematizarmos essas questóes, focalizaremos nosso olhar nas masculinidades encarceradas, a fim de compreender as tensões presentes nesse campo negligenciado pelas políticas de saúde. Tendo em vista que 93,8\% da população carcerária são homens, buscamos colocar em questão sua saúde no sistema prisional, a fim de perceber que saúde é possível na "casa dos homens"; lugar onde as masculinidades criminosas são aprisionadas, reiteradas e (re) produzidas. A “casa dos homens", segundo Daniel Welzer-Lang (2001), refere-se aos territórios onde os homens aprendem a serem homens, afinal, homem não nasce homem: torna-se ${ }^{2}$.

\section{A saúde na prisão}

Já ouviu falar de Lúcifer, que veio do Inferno com moral. Um dia... No Carandiru, não... ele é só mais um. Comendo rango azedo com pneumonia. (Racionais MC's, 2006.)

A vida na prisão: trinta homens numa cela para oito. $\mathrm{O}$ esgoto cloacal regurgita no pavilhão. Ratos, baratas e pombos. Falta colchão, falta chão, falta sabão. $\mathrm{O}$ cheiro é de podre: fezes, urina e mofo.

Diante da face mortífera da instituição prisional, diversos (as) autores (as) citados neste artigo apontam, em suas análises, a rede de complexas relações de assujeitamento do homem tido como criminoso. Tendo como campo de análise a vida na prisão, Cintia Santos e William Peres (2011) afirmam que os presos descreveram a prisão como o lugar onde "o filho chora e a mãe não vê". Há rituais de iniciação nos quais os iniciados introduzem os novos na busca de uma virilidade "verdadeira", o que implica "ter palavra", não agir diferentemente de seu grupo, ter influência sobre os demais e, principalmente, não reproduzir padrōes de relação tidos como femininos, ou seja, falar demais de sentimentos, fraquezas, medos, submissão sexual e mudar de atitude e/ou opinião. Como o espaço prisional só funciona pelos personagens que o compõem, essa "casa dos homens" é composta por múltiplas masculinidades: presos, agentes penitenciários, policiais e outros profissionais.

As diversas representações e práticas relacionadas à vida, à saúde e aos riscos envolvidos no dia a dia são resultantes de múltiplos discursos e práticas, inserindo-se numa lógica peculiar que rege e organiza a vida nessa instituição. A 
prisão, conforme Foucault (1999) está ligada a regramentos que tendem "todos como ela, a exercer um poder de normalização". Cabe então perguntar, no que tange à estratégia política de atenção à saúde voltada ao homem encarcerado: que dispositivos de poder entram em ação?

Dentre eles, destacamos que a Medicina e a Psicologia são usadas como forma de esquadrinhar a perversidade, analisando e estabelecendo os níveis de periculosidade. Essas disciplinas estão mais presentes na medicalização/produção do sujeito da delinquência do que propondo a atenção à saúde. Cabe lembrar, portanto, que "[...] o dispositivo da medicalização é interior à biopolítica, ele age conformando modos de ser”. (IGNÁCIO; NARDI, 2007, p. 89). Compreender os efeitos do dispositivo da medicalização nos modos de subjetivação de distintas masculinidades implica em entender como se atualizam as estratégias biopolíticas no controle da população e na disciplinarização dos corpos.

A visibilidade da população carcerária no país, no que concerne à política de saúde específica para esse corpo social, foi materializada, primeiramente, no Plano Nacional de Saúde no Sistema Penitenciário, instituído pela Portaria Interministerial $\mathrm{n}^{\circ}$ 1777, de 2003, em corresponsabilidade com os Ministérios da Saúde e da Justiça.

Instituídas formalmente no modelo da Estratégia de Saúde da Família, as chamadas Unidades Prisionais de Saúde, no documento oficial, têm a responsabilidade de centrar o atendimento na prevenção e promoção da saúde, bem como na contratação de "Agentes Promotores de Saúde". O atendimento passaria a ser realizado por equipes multiprofissionais disponibilizadas pelas Secretarias de Saúde dos Estados, funcionando 20 horas semanais dentro do espaço da prisão.

O Plano Nacional de Saúde no Sistema Penitenciário é respaldado, em seu documento oficial, nas regras mínimas para o tratamento de prisioneiros aprovadas pelo Conselho Econômico e Social da ONU, que reiteraram o discurso sobre a função da prisão na vida dos homens: "Proteger a sociedade contra o crime, cabendo ao sistema prisional assegurar que, quando egressa do Sistema, essa pessoa seja capaz de respeitar a lei e tornar-se produtiva para a sociedade." (BRASIL, 2004, p.12).

Nesse sentido, Foucault (1999) argumenta que a penalidade não serve pura e simplesmente para reprimir as ilegalidades, mas para diferenciá-las, organizar sua economia geral. Dessa forma, a instituição penal continua a habitar a vida 
dos presos após a saída do cárcere, através de toda uma série de marcações (como o atestado de antecedentes criminais). Quando não são mortos antes mesmo de serem presos, esses homens costumam carregar, como herança do cárcere, sua morte social. Então, por que, a saúde desses corpos importa ao habitarem a prisão? Deparamo-nos então, com os mecanismos de regulação do poder:

Mas tal como a vigilância e junto a ela, a regulamentação é um dos grandes instrumentos de poder [...]. As marcas que significavam status, privilégio, filiaçôes, tendem a ser substituídos ou pelo menos acrescidas de um conjunto de graus de normalidade, que são sinais de filiação a um corpo social homogêneo, mas que tem em si mesmo um papel de classificação, hierarquização e distribuição de lugares. Em certo sentido, o poder de regulamentação obriga à homogeneidade, mas individualiza, permitindo medir os desvios, determinar os níveis, fixar as especialidades e torná-la úteis (FOUCAULT, 1986, p. 82).

$\mathrm{O}$ autor reitera que a sociedade de segurança "engloba, utiliza, explora e aperfeiçoa, sem os suprimir, os dispositivos disciplinares e de soberania" (FOUCAULT, 1986, p.247). Assim, de acordo com os mecanismos de regulação, as doenças tidas como prevalentes entre os homens na prisão vão ser definidas segundo o que é perigoso ou o que pode vir a sê-lo, o que Foucault (2008) classifica como risco. Essa noção também diz respeito ao risco de adoecer, e alguns fatores serão determinados como situações de perigo para o indivíduo. Essas noções não mais puramente seguem o caráter disciplinar de antes, segundo o qual o doente era separado dos não doentes.

Conforme a noção de risco, temos o HIV como uma das maiores causas de preocupação, dentre outras doenças transmissíveis assinaladas pelo Plano Nacional de Atenção Integral à Saúde no Sistema Penitenciário. Segundo o Ministério da Saúde (2004), encontramos na população carcerária um número significativo de casos de DST/Aids, tuberculose, pneumonias e dermatoses. Outras doenças também são citadas no seu documento oficial, como transtornos mentais, hepatites, traumas, diarreia infecciosa, além de outros problemas prevalentes na população adulta brasileira, tais como hipertensão arterial e diabetes mellitus.

Historicamente, conforme afirma Maria Caixeta (2006), a assistência às pessoas privadas de liberdade era vista de forma residual ou parcial, havia apenas a intenção de amenizar os problemas mais frequentes como DST/Aids e realizar imunizações. Com a Resolução no 11, de 07 de dezembro de 2006, estabeleceram-se diretrizes básicas para a detecção de casos de tuberculose dos ingressantes no sistema penitenciário. A partir de então o exame sistemático para 
ingresso no sistema penitenciário deve integrar o conjunto de ações desenvolvidas na "porta de entrada", as quais devem incluir, além do exame médico, atividades de educação em saúde e conscientização, especialmente relativas a HIV/Aids, DSTs e tuberculose. As ações de detecção dessas doenças são de responsabilidade das Unidades Prisionais de Saúde, as quais devem realizar o acompanhamento sistemático, caso exista necessidade de tratamento.

O relatório interno anual de 2008 do Presídio Central de Porto Alegre (TEIXEIRA, 2009) situa os indicadores de atendimento mensal em saúde pelas Unidades Prisionais aos portadores de HIV como correspondendo a 67 por mês, em contraste com os 2.855 apenados diagnosticados com HIV e que ficaram sem acompanhamento, o que denota a insuficiência do cuidado em saúde na prisão em questão. Maria Caixeta (2006), em pesquisa realizada numa Unidade de Saúde Prisional, também observou que a única ação preventiva promovida pela equipe centrava-se na vacinação. Ela também observou que a atenção aos presos concretizava-se no modelo curativo e que os/as profissionais das Unidades Prisionais trabalhavam sem nenhuma interação com os demais trabalhadores da prisão. Um dos indicadores dessa constatação é a inexistência de reuniōes periódicas de equipe para planejamento, qualificação do trabalho e discussão dos casos (CAIXETA, 2006). Diante do trabalho fragmentado, era comum que a ausência de retorno dos presos fosse associada à melhora imediata.

As estratégias de prevenção, quando existem, apontam para "comportamentos de risco", uma designação típica de estratégias de culpabilização e responsabilização dos homens que adquirem doenças sexualmente transmissíveis. Assim, como contraponto, indagamos: manter os indivíduos nas condições apresentadas pelos presídios brasileiros, não estaria, de fato, produzindo "comportamentos de risco"? Esse processo de trabalho se traduz em açóes desvinculadas do contexto, contradição que destaca as condições de vida como produzindo o adoecimento. O documento oficial do Plano de Atenção Integral à Saúde no Sistema Penitenciário indica a necessidade do atendimento em saúde aos sujeitos que já carregam consigo algumas doenças, devido às baixas condiçóes socioeconômicas e aos comportamentos de risco fora da prisão.

Diante das contradições do Plano de Atenção à Saúde, emerge em 2014 a Política Nacional de Atenção Integral à Saúde das Pessoas Privadas de Liberdade no Sistema Prisional, instituída pela Portaria no 1, de 2 de janeiro de 2014. 
Através dos princípios da integralidade e da intersetorialidade, busca-se ampliar e qualificar o acesso à saúde das pessoas privadas de liberdade, tanto nas equipes de saúde prisional quanto em toda a rede de atenção à saúde, inclusive no cadastro e acesso aos serviços de atenção básica após o cumprimento da medida. A saúde é tomada em sua violação de condições adequadas ao cumprimento de medida e a falta de acesso a bens sociais.

Considerando que essa política de saúde foi elaborada pelo Grupo Condutor Interministerial, conforme Portaria Interministerial no 1.679, de agosto de 2013, a Política Nacional de Atenção Integral à Saúde das Pessoas Privadas de Liberdade contempla a totalidade da população prisional, incluindo os que estão em regime fechado, aberto, prisão provisória e os detidos em delegacias. Ademais, incluemse nas ações de promoção e prevenção em saúde os trabalhadores em serviços penais, os familiares e demais pessoas privadas de liberdade.

Essa política não busca apenas prevenir e reduzir o índice de doenças sexualmente transmissíveis, mas englobar medidas de atenção à saúde relacionadas aos diversos fatores de adoecimento e agravos em saúde. Ela indica a necessidade de açôes intersetoriais que envolvam educação, trabalho e segurança, além da humanização do cuidado e das condiçôes de vida no sistema prisional, com participação popular e controle social. Esses princípios e diretrizes não estavam contemplados no Plano Nacional de Atenção Integral à Saúde no Sistema Penitenciário.

Muitos são os desafios para materializar a atenção à saúde no território prisional, à luz da Portaria n ${ }^{\circ} 1$ de 2014. Inicialmente, as Unidades Prisionais de Saúde tinham o objetivo de evitar a mortalidade dos presos por doenças e foram criadas como estratégias para reduzir a incidência de doenças como tuberculose, Aids, doenças respiratórias, entre outras. Airton Michels, secretário de segurança do Rio Grande do Sul (RS), em entrevista para jornal Sul21, afirma:

Implantamos duas Unidades Básicas de Saúde lá dentro em agosto de 2011. E isso já
tem resultados. Em 2009, morreram 24 presos de causas naturais dentro do Presídio
Central. Em 2010, morreram 15. Ano passado morreram seis e este ano não morreu
nenhum por enquanto. Estamos fazendo alguns paliativos enquanto elaboramos as
políticas de resolução do problema dos presos. (DUARTE, 2012).

A preocupação com a integridade física do preso, para aqueles que fazem parte da instituição, está focada apenas em não deixá-lo morrer lá dentro. Valquíria Teixeira (2005) afirma que prevalece, assim, o ideário de que as ações e instituições do Estado são resolutivas em seus objetivos. Em contraste, temos o alto índice de 
morbimortalidade por causas externas da população masculina pobre e negra; podemos dizer que, segundo o relato do secretário de segurança, poucos morreriam dentro da prisão. Será? Mas em que condições os sujeitos vivem?

Em reportagem datada de outubro de 2012, ressalta-se a contradição:

O Conselho Nacional de Justiça (CNJ), por meio do Departamento de Monitoramento e Fiscalização do Sistema Carcerário e do Sistema de Execução de Medidas Socioeducativas (DMF), envia, nesta sexta-feira (26/10), ofícios ao governador do estado do Rio Grande do Sul, Tarso Genro, e ao secretário estadual da Segurança Pública, Airton Michels, em que cobra providências para frear a onda de mortes de detentos no sistema carcerário gaúcho. Segundo dados da Vara de Execuções Criminais da capital, nos últimos quatro anos, 278 presos morreram nos 25 presídios da região metropolitana de Porto Alegre, sendo que $89 \%$ dos óbitos foram causados por doenças (VASCONCELLOS, 2012).

De acordo com os dados da Vara de Execuções Criminais da capital, dos 278 presos registrados em óbito, 115 detentos morreram por insuficiência respiratória, 112 por Aids, 65 por broncopneumonia, 48 por pneumonia, 42 por tuberculose, 29 por septicemia. Há também casos de insuficiência renal (12 mortos), insuficiência cardiorrespiratória (11), meningite (11), hepatite (10), cirrose hepática (8) e diabetes (8). Não bastasse a falta de atenção à saúde, a violência também matou: houve 12 enforcamentos, 5 estrangulamentos e 4 mortes por arma de fogo. Entre todos os 278 óbitos registrados, $71 \%$ foram de detentos com menos de 40 anos de idade.

Ademais, o tratamento nos hospitais obedece ao jugo moral dos profissionais de saúde. Denise de Azevedo Irala et al. (2010) investigaram as percepções dos profissionais de saúde responsáveis pela atenção à saúde dos apenados. Os autores perceberam que, sob o prisma do profissional, o preso era alvo de compaixão e também de críticas pela sua condição de criminoso. Contudo, muitos relatavam as péssimas condições de saúde em que os presos chegavam ao hospital. Assim, o discurso de que a prisão faz viver é retificado perante novos dados, que explicitam que a mortalidade que não ocorre dentro do espaço prisional ocorre no momento da internação do preso.

A regulação do corpo passa por uma punição que atinge a alma, delimitando as fronteiras do corpo. Os mecanismos de poder que operam nessa população influem diretamente na saúde desses homens. A convivência em tempo integral, segundo Valquíria Teixeira (2009), somada à falta de espaço físico, faz com que os apenados percam sua individualidade, no sentido de que as práticas corporais 
têm de ser readaptadas a um convívio coletivo imposto. De acordo com a autora,

para resistir às condições de vida deploráveis, os presos mantêm uma organização coletiva de práticas de cuidado. Enquanto regras propostas pelo próprio coletivo de presos, estes precisam tomar banho uma vez ao dia, limpar as galerias e não utilizar o banheiro enquanto outro estiver comendo. Adquirir os produtos para a efetivação dessa rotina não é simples, pois muitos presos alegaram, segundo a autora, que, com as revistas gerais, realizadas mensalmente, muitos produtos, colchôes e pertences tornam-se inutilizáveis após manipulação da polícia.

Ainda segundo a autora, a violência explícita já não é permitida entre presos, salvo raros casos decididos pela "prefeitura". Prefeitura é a nomeação dada a cada galeria. Ou seja, os presos ocupam politicamente as galerias como se fossem cidades; em cada galeria há uma prefeitura com homens designados, hierarquicamente, a cada uma das tarefas da "cidade". Essa hierarquia organiza o responsável pela faxina, o mestre paneleiro, o auxiliar do mestre paneleiro, o organizador das visitas íntimas (TEIXEIRA, 2009). Se "onde há poder, há resistência" (FOUCAULT, 1995), as masculinidades encarceradas tentam evitar a morte social nesse espaço, ao deslocarem a lógica do biopoder para as demandas específicas desses homens organizados por si próprios. Ao mesmo tempo, essa forma de gerenciamento da vida coletiva é um efeito de poder de uma economia geral sobre o corpo da população prisional. Tendo em vista que há toda uma organização própria das cidades, como as "prefeituras" se organizam em relação à saúde da população?

Os agentes penitenciários são personagens primordiais no acolhimento das demandas dos homens por trás das grades. Paula Foltran (2010), Rosalice Lopes (2002), Maria Caixeto (2006) e Vilma Diuana (2008) sublinham que as demandas não são verbalizadas primeiramente aos profissionais das Unidades de Saúde Prisional, pois estes nem mesmo circulam pelas galerias. Cabe aos agentes penitenciários organizar uma lista de encaminhamentos para atendimento do preso no serviço. Para obterem atendimento com qualquer profissional de saúde, o preso deve entregar um bilhete de solicitação de atendimento ao agente penitenciário, uma vez que, para acessar qualquer dos serviços oferecidos dentro da penitenciária, é necessária escolta.

Conforme descreve Vilma Diuana (2008), nesse ambiente onde a circulação de detentos é restrita e os profissionais de saúde evitam circular, os agentes de segurança penitenciária exercem um papel diferenciado no que se refere 
942 à regulação do acesso à saúde. Muitas vezes são os agentes de segurança penitenciária que julgam a necessidade de atendimento a partir do pedido do preso e facilitam ou dificultam esse acesso. Por outro lado, no ambiente confinado das prisões, estão em contato cotidiano e direto com os presos e expostos, como eles, aos riscos infecciosos, em especial à tuberculose. Assim, as relações poder-saber relativas à medicalização são atravessadas pelo poder-saber da polícia no contexto prisional. Aquele que controla a política de escolta controla também o tipo de acesso possível aos serviços disponíveis. Sob a justificativa de que falta pessoal efetivo, privilegiam-se os atendimentos de médicos e dentistas. Não são todos que chegam a ser atendidos, somente aqueles que passam pelo crivo policial do merecimento. Ou seja, o atendimento dependerá do tipo de relacionamento estabelecido entre o agente e o interno (CAIXETA, 2006). Submetida à ordem da barganha, a saúde funciona como elemento de troca e negociação para manutenção da ordem e da disciplina no cárcere.

Dentre outros agravantes no itinerário dos homens encarcerados que buscam a intervenção dos profissionais de saúde das Unidades de Saúde Prisional, salientase: 1) a falta de retorno para que haja continuidade no tratamento, devido ao fato de o agente penitenciário acreditar que em apenas uma consulta o usuário já foi suprido em sua demanda de saúde (CAIXETA, 2006); 2) o temor das doenças transmissíveis a que os agentes relatam estar expostos, sendo a tuberculose a doença mais ameaçadora não só entre os detentos, mas também entre os agentes (DIUANA, 2008); 3) o atendimento condicionado à presença de sintomas verificáveis, uma vez que os presos muitas vezes são percebidos como incapazes, indolentes e dissimulados. Por exemplo, de acordo com Vilma Diuana (2008), o sofrimento psíquico parece não ser percebido como motivo suficiente para suscitar a assistência à saúde ou para evidenciar que algo não vai bem. Ainda de acordo com a autora, o esquadrinhamento do espaço prisional (lugares de presos/ dentro e lugares de agentes de segurança penitenciária/fora) e a separação "nós"/ agentes de segurança penitenciária e "eles"/presos (guarda não deve tocar em preso) parece proporcionar a impressão de um risco sob controle. Sob o prisma do agente penitenciário em relação ao trabalho desempenhado, o risco não concerne apenas à contaminação pelas doenças que preocupam a todos, mas à contaminação pela sujeição criminosa. Daí a necessidade de produzir estratégias defensivas que os afastem dos homens apenados. 
"Eles [os presos] parecem entender apenas a linguagem da ignorância, e o guarda que

não age dessa forma passa a ser visto [pelos presos] como 'guarda bombom"” (agente de segurança penitenciária). No contexto das relaçóes agente de segurança penitenciária/ detento, o cuidado aparece como fraqueza, como sinal de rebaixamento e submissão, inaceitável para a manutenção da imagem de "força" e "poder" reivindicada pelos dois polos dessa interação (DIUANA, 2008, p. 189).

Como mal contagioso, o contato direto com o preso, pelo compartilhamento forçado do espaço, pela convivência obrigatória e pelo confinamento, favorece o sentimento de exposição a uma possível contaminação, que se estende do plano sanitário ao das identidades e do âmbito dos corpos ao psíquico e ao moral.

Tanto os presos como os agentes penitenciários estão expostos a reiterarem os padrōes heteronormativos de masculinidades como forma de sobrevivência perante as contingências locais da prisão. Qualquer sinal de fragilidade ou qualquer outro atributo que não cole ao regime de masculinidade imposto pode trazer graves consequências, como a humilhação ou mesmo a morte. $\mathrm{O}$ masculino é, ao mesmo tempo, submissão ao modelo e obtenção de privilégios.

Rosalice Lopes (2002) afirma que muitos agentes, ao longo dos anos, passam a apresentar alterações comportamentais, tornam-se alcoolistas, dependentes de drogas ilícitas, antidepressivos e ansiolíticos. Outros se envolvem em práticas ilegais e descobrem, tardiamente, como é tênue a linha que separa a conduta criminal da não criminal. Ademais, todos esses homens que circulam nas galerias, segundo Vilma Diuana (2008), são confrontados com a impotência perante o sujo e o tóxico, que aparecem como algo imposto e que, interiorizado, contamina as identidades, associando-as ao lixo e ao sujo, àquilo de que se quer distância.

Por fim, não poderíamos esquecer-nos do lugar que as mulheres ocupam na construção dessas masculinidades viris na prisão, enquanto interlocutoras das necessidades desses homens, inclusive no âmbito da saúde. São as mulheres visitantes que mobilizam muitas vezes a marcação de consultas, exames e outros procedimentos da área da saúde não disponíveis na penitenciária. Paula Foltran (2010) conclui que está a cargo das mulheres em contato com os presos efetivar os encaminhamentos.

Conforme Valquíria Teixeira (2009), a visita é relatada como tão indispensável para a vida na prisão que, aos companheiros de cela que não recebem visita, são disponibilizados por outros presos materiais necessários para cuidado diário (higiene, roupas, colchão), além do auxílio dos para a resolutividade dos 
encaminhamentos que se fizerem necessários. Nada é cobrado em troca, exceto que o sujeito retribua a outro a mesma ajuda quando for necessário. Essa questão revela que, na "casa dos homens", também se percebem relações de solidariedade.

A mulher, assim, é aquela que serve de ponte entre o homem e sua heterossexualidade e com os atributos de masculinidades dissociados da vida do crime. Além disso, a visita permite a verbalização das necessidades que não são legitimadas, como as necessidades em saúde. Desse modo, temos novamente a figura feminina assumindo seu posto de cuidadora do corpo social masculino, sendo elemento-chave para as formas de viver dos presos nos meandros biopolíticos do encarceramento. Sublinha-se que a PNAISH, quando promove em seus enunciados que os homens não se cuidam, aponta como solução que cabe às mulheres cuidar dos homens, cuidado refletido na mulher que deve levar seu companheiro para o serviço da atenção básica. Pontua-se, assim, a necessidade de estudos que contemplem a vida das mulheres enquanto visitantes desses homens encarcerados, e também de estratégias que fomentem o protagonismo e o direito do acesso à saúde.

\section{Considerações finais}

O homem criminoso materializa-se, de fato, como objeto de atenção para a saúde pública, bem como para outras políticas intersetoriais? Acompanhando as relações de força entre os sujeitos envolvidos no cuidado à saúde no regime prisional, verificamos que, num espaço essencialmente masculino, cuidar da saúde é o último predicado atribuído às masculinidades viris. Há um controle desses corpos que repudia aqueles que demandam cuidados.

Ademais, o homem criminoso tem acesso restrito ao Sistema Único de Saúde. O cuidado integral aos homens encarcerados, pressuposto da política de atenção básica, ainda não se concretiza devidamente. No contexto atual, o acesso dos presos à saúde é mediado pelos agentes penitenciários e pelos próprios presos, contrariando a política que rege que esse papel cabe aos profissionais de saúde. Em muitos casos, o atendimento em saúde aos presos enfermos ocorre tardiamente, geralmente após a doença atingir gravidade, sendo que o tratamento não é mais possível nas Unidades de Saúde Prisional, demandando transferência do paciente para hospitais externos à prisão. 
Os aspectos supracitados contradizem o enunciado da PNAISH de que o homem é o principal culpado por não cuidar de sua saúde. $\mathrm{Na}$ sequência discursiva que acompanha o homem criminoso, encontramos o caráter de réu atribuído a esses homens, tanto por serem tomados como incapazes de cuidar da própria saúde como por serem autores das situações de violência. A criminalidade, enquanto um dispositivo de poder que conforma diversas instituições, vai além do espaço da prisão e das políticas da segurança pública. Conforme Gilead Tavares (2011), as instituições e políticas sociais são perpassadas pelo dispositivo da criminalidade que produz efeitos nos corpos suspeitos. A estratégia principal não seria de fato transformar a realidade social, e sim de localizar, separar e identificar aqueles que passarão a ser chamados de perigosos.

Nesse sentido, percebemos que ter acesso à assistência em saúde, ou não ter, também é uma estratégia de poder atrelada ao dispositivo de criminalidade. A produção das condições de saúde se dá muito além das condições físicas. De fato, elas são marcas do poder que inscrevem os sujeitos em determinadas posições identitárias. Em uma análise intersetorial das políticas públicas de saúde, assistência social e segurança pública enquanto estratégias biopolíticas, direcionadas preferencialmente aos pobres, ressaltamos seu efeito transversalizador na produção de masculinidades.

A PNAISH sinaliza muito brevemente os homens sob o regime do cárcere como uma de suas linhas de cuidado. Já a Política de Atenção Integral à Saúde de Pessoas Privadas de Liberdade amplia o escopo de seu objeto de ação, através do entendimento de que a produção de saúde no sistema prisional insere-se numa conjuntura social em que múltiplos fatores de risco e atores sociais estão envolvidos. Sinalizamos a necessidade de que a Saúde do Homem, enquanto uma política de saúde, também possa criar outros dispositivos que ampliem seu objeto de cuidado e as estratégias para a ampliação e qualificação do acesso dos homens, principalmente no que se refere aos serviços de Atenção Básica.

A transversalidade entre a saúde prisional e a saúde do homem emerge sobretudo como uma possibilidade da rede de atenção em saúde, acolher o homem privado de liberdade enquanto sujeito que tem direito de acesso aos serviços de saúde dentro e fora do espaço prisional. Não há como implantar uma linha de cuidado à saúde dos homens sem problematizar esses e outros atravessadores. 
A amplitude da temática exposta neste artigo, obviamente, não foi esgotada nestas breves linhas. Enfatizamos, sobretudo, a necessidade urgente de estudos nesse campo que discutam o que a violência institucional tem a nos dizer sobre a saúde dos homens. ${ }^{3}$

\section{Referências}

BEAUVOIR, S. O segundo sexo. V. 1. Rio de Janeiro: Difusão Europeia do Livro, 1970. 309p. BRASIL. Ministério da Justiça. Resolução no 11, de 07 de dezembro de 2006. Diretriz Básica para a Detecção de Casos de Tuberculose entre ingressos no Sistema Penitenciário nas Unidades da Federação. Disponível em <file://C:/Users/Ana\%20Silvia/ Downloads/2006resolu11.pdf> . Ministério da Saúde. Departamento de Ações Programáticas Estratégicas. Plano Nacional de Saúde no Sistema Penitenciário. Brasília: Ministério da Saúde, 2004.

. Departamento de Ações Programáticas Estratégicas. Política Nacional de Saúde do Homem: princípios e diretrizes. Brasília: Ministério da Saúde, 2009.

. Saúde do Homem. Brasília: Ministério da Saúde, 2009.

BUTLER, J. Problemas de gênero: feminismo e subversão da identidade. Rio de Janeiro: Civilização Brasileira, 2008. 236p.

CAIXETA, M.C. Plano Nacional de Saúde no Sistema Penitenciário: análise do processo de sua implementação no distrito federal, 2006. 39p. Trabalho de Conclusão de Curso (Bacharelado em Serviço Social) - Instituto de Ciências Humanas Universidade de Brasília, Brasília, 2006.

CARRARA, S. Comentários diagonais sobre a emergência dos homens na pauta da Saúde Coletiva. Ciência \& Saúde Coletiva. Rio de Janeiro, v. 10, n. 1, p. 28-29, 2005.

CARRARA, S.; RUSSO, J.A.; FARO, L. A política de atenção à saúde do homem no Brasil: os paradoxos da medicalização do corpo masculino. Physis: Revista de Saúde Coletiva. Rio de Janeiro, v. 9, n. 3, p. 659-678, 2009.

COIMBRA, C.; NASCIMENTO, M.L. Ser jovem, ser pobre é ser perigoso? Jovenes: Revista de Estudios sobre Juventud. México, v. 9, n. 22, p. 338-355, 2005.

COUTO, M. et al. O homem na atenção primária à saúde: discutindo (in)visibilidade a partir da perspectiva de gênero. Interface: Comunicação, Saúde, Educação. Botucatu, v. 4, n. 33, p. 255-70, 2010.

DIUANA, V. et al. Saúde em prisões: representações e práticas dos agentes de segurança penitenciária no Rio de Janeiro, Brasil. Caderno de Saúde Pública. Rio de Janeiro, v. 24, n. 8, p. 1.887-1.896, 2008. 
DUARTE, R. Não saio do cargo sem resolver Presídio Central, diz Airton Michels. Jornal

Sul 21, 6 de agosto de 2012. Disponível em: http://www.sul21.com.br/jornal/nao-saio-docargo-sem-resolver-presidio-central-diz-airton-michels/ Acessado em: 07 fev 2013.

FIGUEIREDO, W. Assistência à saúde dos homens: um desafio para os serviços de atenção primária. Ciência e Saúde Coletiva. Rio de Janeiro, v. 10, n. 1, p. 105-9, 2005.

FOLTRAN, P.J. A visita nas unidades prisionais e seu papel na mediação do acesso aos direitos da pessoa presa: uma reflexão acerca das desigualdades de gênero na política penitenciária. In: SEMINÁRIO INTERNACIONAL FAZENDO GÊNERO, 9., Florianópolis, 2010. Anais do Seminário Internacional Fazendo Gênero, Florianópolis, UFSC, 2010. p. 103-111.

FOUCAULT, M. A arqueologia do saber. Rio de Janeiro: Forense Universitária, 1986. 239p.

. O sujeito e o poder. In: DREYFUS, H.L.; \& RABINOW, P. Michel Foucault: uma trajetória filosófica: para além do estruturalismo e da hermenêutica. Rio de Janeiro: Forense-Universitária, 1995. p.231-249.

. Segurança, território, população. São Paulo: Martins Fontes, 2008. 572p.

Vigiar e punir: nascimento da prisão. 20 ed. Petrópolis: Vozes, 1999. 264p.

IGNÁCIO, V.T.G.; NARDI, H.C. A medicalização como estratégia biopolítica: um estudo sobre o consumo de psicofármacos. Psicologia e Sociedade. Porto Alegre, v. 19, n. 3, p. 88-95, 2007.

IRALA, D. et. al. Trabalho em saúde com pacientes apenados: sentidos metafóricos gerados no contexto hospitalar. Acta Revista de Enfermagem. Rio de Janeiro, v. 24, n.2, p. 206-12, 2011.

LOPES, R. Psicologia jurídica o cotidiano da violência: o trabalho do agente de segurança penitenciária nas instituiçōes prisionais. Psicologia América Latina. México, v. 0, p. 1-8, 2002. Disponível em: http://psicolatina.org/Cero/psicologia_juridica.pdf Acesso em: 03 maio 2014.

LOURO, G. L. Um corpo estranho: ensaios sobre sexualidade e teoria queer. Belo Horizonte: Autêntica, 2004. 96p.

BRASIL. Ministério da Justiça. Execução penal. Sistema Integrado de Informações Penitenciárias Info Pen, 2012.

MISE, M. Crime, sujeito e sujeição criminal: aspectos de uma contribuição analítica sobre a categoria "bandido". Lua Nova. São Paulo, v. 79, p. 15-38, 2010.

MISKOLCI, R. A teoria queer e a sociologia: o desafio de uma analítica da normalização. Sociologias. Porto Alegre, v. 11, n. 21, p. 150-82, 2009.

NASCIMENTO, M.; SEGUNDO, M.; BAKER, G. Reflexões sobre a saúde dos homens jovens: uma articulação entre juventude, masculinidade e exclusão social. In: GOMES, R. (Org.). Saúde do Homem em debate. Rio de Janeiro: Fiocruz, 2011.

RACIONAIS MC'S. 1000 trutas 1000 tretas. Cosa Nostra, CN 007, 2006. 
SANTOS, C.; PERES, W. Tecnologias de gênero, masculinidades e aprisionamentos na execução penal. Revista Internacional., Florianópolis, v. 8, n. 1, p. 185-199, 2011.

SARTI, C. A; BARBOSA, R. M. \& SUAREZ, M. M. Violência e gênero: vítimas demarcadas. Physis, Rio de Janeiro, v. 16, n. 2, p. 167-183, 2006.

SEFFNER, F. Derivas da Masculinidade: Representação, Identidade e Diferença no Âmbito da Masculinidade Bissexual. 2003. 260p. Tese (Doutorado em Educação) Faculdade de Educação, Universidade Federal do Rio Grande do Sul, Porto Alegre, 2003.

TAVARES, G. M. O dispositivo da criminalidade e suas estratégias. Fractal, Rio de Janeiro, v. 23, n. 1), p. 123-136, 2011.

TEIXEIRA, V. B. Adaptando o corpo ao espaço de confinamento: um estudo antropológico sobre práticas corporais no presídio central de Porto Alegre. 2009. 88p. Trabalho de Conclusão de Curso (Bacharelado em Ciências Sociais) - Instituto de Filosofia e Ciências Humanas, Universidade Federal do Rio Grande do Sul, Porto Alegre, 2009.

VASCONCELLOS, J. Mortes de detentos em RS deverão ser explicadas. CNJ, 26 de outubro de 2012. Disponível em: http://www.cnj.jus.br/noticias/cnj/21828:mortes-dedetentos-em-rs-deverao-ser-explicadas. Acesso em: 03 fev 2013.

WAISELFISZ, J. Mapa da violência. Os jovens do Brasil. São Paulo: Instituto Sangari, 2012. WELZER-LANG, D. "Nós, os caras." Entrevista com Daniel Welzer-Lang. Revista do CLAM, 2009. Disponível em <http://www.clam.org.br/publique/cgi/cgilua.exe/sys/start. htm? infoid $=5371 \&$ sid $=4>$. Acesso em: 03 maio 2014 .

. A construção do masculino: dominação das mulheres e homofobia. Revista Estudos

Feministas. Florianópolis, v. 9, n. 2, p. 460-482, 2001.

\section{Notas}

${ }^{1} \mathrm{O}$ presente estudo é resultado de dissertação de mestrado. A formação foi financiada por bolsa de estudos do Programa CAPES/REUNI.

${ }^{2}$ Lembrando aqui a frase célebre de Simone de Beauvoir (1970).

${ }^{3}$ H.B. dos Santos realizou de forma mais exaustiva a análise dos documentos. Ambos os autores participaram na redação do artigo e aprovaram a versão final a ser publicada, sendo que H.C. Nardi teve papel mais dedicado à revisão crítica do conteúdo conceitual. 


\section{Abstract}

\section{Masculinities between killing and dying: what health has to do with it?}

The main cause of illness and death in the Brazilian young male population is external. Men involved in the criminal context die due to violence or are exposed to prison violence, the focus of this paper. In order to understand the diagram of forces involved in the production of criminalized masculinities, we aim at understanding which health is possible for these men whose fate, almost invariably, is social or physical death. Methodologically, this article is inspired by Michel Foucault perspective, analyzing, in the Brazilian biopolitical context, the discussion about public health policies directed towards men, such as Man's Health Care Policy, the Plan for Health Care in Prisons and the new National Health Care Plan for People in Prisons. The analysis indicates that race and class inter-sectionalities are directly involved in the production of incarcerated men's health. Recent data reveal that men get sick in prisons and die outside due to the lack of proper assistance. In this sense, the National Health Care Plan for Incarcerated People replaces the debate on health rights mainly related to integral and inter-sectorial aspects.

Key words: masculinities; prison; man's health. 